[2] Tsai A.P., et al., Mat. Trans. JIM 31 (1990) 98; Tsai A.P., A. Inoue \& T. Masumoto, Phil. Mag. Lett. 62 (1990) 95.

[3] Kycia S.W., et al., Phys. Rev. B 48 (1993) 3544 .

[4] de Boissieu M., et al., Phil. Mag Lett. 65 (1992) 147; Yokoyama Y., et al., Mater. Trans., Japan Inst. Metals 33 (1992) 97; Boudard M., et al., Phil. Mag Lett. 71 (1995) 11.

[5] Boudard M., et al., Phil. Mag. Lett. 64 (1991) 197; Boudard M., et al., J. Phys.: Condens. Matter 4 (1992) 149.

[6] Janot C. \& de Boissieu M., Phys. Rev. Lett. 72 (1994) 1674.

[7] Chernikov M.A., et al., Europhys. Lett. 21 (1993) 767; Pierce F.S., Poon S.J. \& Guo Q., Science 261 (1993) 737; Chernikov M.A., et al., Phys. Rev. B 48 (1993) 3058; Klein T., et al., Phys. Rev. Lett. 66 (1991) 2907; [15] Lanco P., et al., Europhys. Lett. 18 (1992) 227; Mayou D., et al.,Phys. Rev. Lett. 70 (1993) 3915.

[8] Poon S. J., Adv. Phys. 41 (1992) 303.

[9] Janot C., Phys. Rev. 53 (1996) 1.

[10] Cornier-Quiquandon M., et al., Phys. Rev. B 44 (1991) 2071.

[11] Boudard M., et al., J. Phys.: Condens. Matter 7 (1995) 7299; and Phys. Scripta T57 (1995) 84.

[12] Suck J. B., J. Non-Cryst Solids 153-154 (1993) 573.

[13] Dubois J.M., et al., J. Mater. Res. 73 (1992) 38.

[14] Chernikov M.A., Bianchi A. \& Ott H.R., Phys. Rev. B 51 (1995) 153; Perrot A. \& Dubois J.M., Ann. Chim. Fr. 18 (1993) 501.

[15] Perrot A. \& Dubois J.M., Proc. 6th Int. Conf. on Quasicrystals, Eds.: C. Janot \& R. Mosseri (World Scientific, 1995) 586.

[16] Pierce F.S., Guo Q. \& Poon S.J., Phys. Rev. Lett. 73 (1994) 2220.

[17] Lanco P., PhD Thesis, Univ. Joseph Fourier, Grenoble (1993).

[18] Biggs B.D., Poon S.J. \& Munirathman N.R., Phys. Rev. Lett. 65 (1990) 2700.

[19] Boursier D., et al., C.R. Acad. Sci. Paris 319 II (1994) 409.

[20] Degiorgi L., et al., Solid State Comm. 87 (1993) 721.

[21] Basov D.N. et al., Phys. Rev. Lett. 73 (1994) 1865.

[22] Eisenhammer T., in [15] 766.

[23] Kang S.S. \& Dubois J.M., Phil. Mag A 66 (1992) 161; Dubois J.M., Kang S.S. \& Perrot A., Mater. Sci. Engng. A 179-180 (1994)122.

[24] Kang S.S. \& Dubois J.M., Europhys. Lett. 18 (1992) 46.

[25] Dubois J.M., et al., Ann. Chim. Fr. 19

(1994) 3 .

[26] Kang S.S., Dubois J.M. \& von Stebut J., J.

Mater. Res. 8 (1993) 2471.

[27] Von Stebut J., Strobel C. \& Dubois J.M., in [15] 702.

[28] Massiani Y., Ait-Yaazza S. \& Dubois J.M. in $[15] 788$.

[29] Chang S.L., et al., Surface Sci. 337 (1995) 135.

[30] Sedel L., Janot C. \& Dubois J.M. (to be published).

[31] For information, contact: J.M. Dubois, LSG2M, Ecole des Mines, Parc de Saurupt, F54042 Nancy Cedex.

\title{
Spread Your Net, and Wings
}

Denis Weaire, Professor of Natural and Experimental Philosophy at Trinity College, Dublin, who steps down shortly as the Chairman of the Physics Panel for the Research Training Networks activity of the European Union's Training and Mobility of Researchers Programme, argues that physics networks need to pay more attention to industrial participation.

All over Europe, the research networks supported by the Human Capital and Mobility (HCM) Programme of the European Union (EU) are filing their final reports and closing their accounts. For many individuals this was their first taste of science on a European scale, and they like it. Sceptics have said that the programme's main beneficiaries were the airlines, but those closest to the ground know that it has undoubtedly quickened the pace of international collaboration.

HCM was never intended to scatter its funds as widely and thinly as it did. The tortuous negotiations which preceded it resulted in compromises which left its description so vague as to defy interpretation at some points. Even the panels which were called to select the successful proposals were unsure of their mission and priorities. Accordingly, in gambling parlance, they played the field.

Proposers were disgruntled to receive news of grants below their expectation levels. Since then, many of them have come to appreciate the benefits of marginal funding to facilitate cooperation. Is this not a particularly appropriate role for the EU ?

The original idea of strong, well funded networks was reinstated in the successor to HCM. This was dubbed the Training and Mobility of Researchers (TMR) Programme, as the European Commission pursued its relentless search in the dictionary for new names. Lower as well as upper bounds on funding levels were fixed so that the eventual grants would lie in the range of 1-2 MECU per network. The tendency of panels to throw bread upon the waters was to be held in check. Criteria for selection were clear. The race was now on.

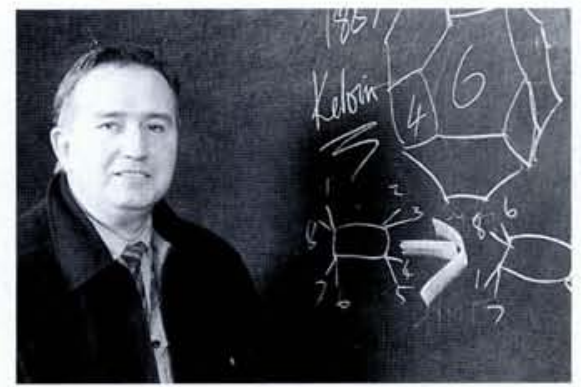

The eventual $6.4 \%$ success rate for the first round of network applications caused much dismay, but was surely predictable. To alleviate the repetition of this orgy of ritual rejection, the allocation of funds to the next two rounds have been rolled into one, and the deadline deferred until 16 September 1996. The success rate should roughly double, but the competition will still be tough. Is it worth applying?

Rounding up a flock of network partners and getting them all to point in the same direction is no easy task. While the proposal forms (first gate in the sheepdog trial) have been greatly improved, they still pose puzzles for the uninitiated. Many will rightly conclude that it is more realistic and efficient to try to attract individual TMR Research Training Grants - that part of the programme had an average success rate of close to $25 \%$ for postdoc fellowships in its first two rounds (physicists amounted to approximately $22 \%$ of applicants, and achieved a satisfactory $24 \%$ success rate).

If you do decide to conceive a prospective network (or dust off an old one) you should bear in mind that all three words training/mobility/research must be respected. In the end, having covered all the bases, remember that selection is by scientific peer review. The peers involved will have spent three days in Brussels scrutinising the proposals, discussing their merits, and consuming mussels. As selection fatigue sets in they will look for exciting and challenging themes, startling originality, potential for progress and strong interactions of all kinds: theory with experiment, country with country, big centres of excellence with small ones.

You should think hard about the possible involvement of industry. TMR is neutral as regards basic and applied science. By default it has become a major morale booster for basic science, but its future would be better assured if it were more balanced in this respect.

Physics presently suffers a particular malaise in its relations with industry,

D.L. Weaire, was elected as the EPS President-Elect at the EPS Council in Lisbon on 22-23 March. 
despite its enormous past contributions to our economies. This was reflected in the applications received: industrial participation was minimal. Excuses can be made for this but surely we need to build, or rebuild, bridges over the gulf between us and our industrial colleagues. What better way than with a network, under whose auspices the two sides can identify and develop their shared interests?

Stimulation, SCIENCE and HCM (TMR's predecessors) and TMR itself have made a unique contribution to demolishing barriers between scientists. National funding agencies remain trapped in chauvinist mentalities, for the most part. TMR lets a lucky few spread their wings. Its continuation into the next Framework Programme deserves strong political support.

\section{Training and Mobility of Researchers}

\section{Networks to Train}

The European Union (EU) Training and Mobility of Researchers (TMR) Programme, part of the EU's 4 th Framework Programme 1994-98, comprises four activities (networks, training grants, access to facilities, and conferences). Networks in its first round that closed in June 1995 netted 1427 eligible proposals. Following review by the seven disciplinary panels, only $91(6.4 \%)$ were selected, largely owing to budgets designed to increase significantly the average funding per network from the 250-500 kECU range typical for networks in TMR's predecessor (Human Capital and Mobility - HCM) so as to provide more depth, such as support for postdocs.

The TMR first round involved a larger number of proposals than the equivalent stage in HCM (HCM received some 2199 in its entire operational period of about 3 years) because fields such as economics are now eligible and others have gained experience, because teams make several proposals, and because the delayed launching of TMR led to a builtup demand.

A total of 332 proposals (close to the equivalent HCM level of some $25 \%$ ) were in physics, and only $6 \%$ were selected (as compared to over $30 \%$ for $\mathrm{HCM}$ ). Peter Kind, who manages the network activity, has indicated that networks were not selected on the basis of targeted fields since targeting has not been chosen as an eligibility criterion by the Council of Ministers. It is difficult to define and set targets in science in a programme that is intended to be bottom-up (i.e., based on projects put forward by scientists).

TMR has decided to combine the final two selection rounds, to reduce the period for a network from 4 to 3 years (justifiable since 3 years still gives continuity into the 5 th Framework), and to reduce the funding per team per year from 50-80 kECU to $40-70 \mathrm{kECU}$ (mostly by reducing salary support for experienced scientists so as not to diminish the emphasis on the training of young people). The result will be a further 160 networks funded, with an average of 1.25 MECU per network (as compared to $1.6 \mathrm{MECU}$ for the first round) and about 25 postdocyears per network (instead of the present 30).

Some $60 \%$ of a typical network's salary costs are for training young scientists. So applicants will be asked to explain why training is needed. Networks are usually multidisciplinary. But it will not be necessary for each individual component of a network to justify why its particular area needs trained people. It will instead be the overall picture that is considered. Peter Kind indicates that in addition to offering real interaction at the working level, networks should provide training opportunities for young scientists (not simply employment for a pair of young hands). The training should benefit from being inside a multidisciplinary, international project involving complementary teams so that young collaborators encounter a broad range of challenging problems.

The guidelines for TMR networks in the next (and last) selection round closing on 16 September 1996 are: Size - at least 5 research teams, 3 countries, $1 \mathrm{EU}$ team, and 3 established teams. Financing $-100 \%$ additional costs; 40-70 kECU/team/year; up to $15 \mathrm{MECU}$ total; up to 3 years; no more than $40 \%$ of finance to teams in one country.
Grants Underexploited

Framework programmes other than TMR offer mobility grants ( 118 were awarded in early 1996 , on the same terms as TMR Research Training Grants, by six specific programmes). The EC advises applicants to contact programme officers to see if it best to apply to a specific programme or to TMR.

TMR of course offers by far the largest number of fellowships. Of the roughly 5700 eligible proposals dealt with in the first three rounds (June, September December 1995 calls), some 1100 were in physics; they had a success rate of $22 \%$ for the first two rounds.

Barry McSweeney, who was recently appointed Head of the TMR Fellowship activity, says that reducing the time to process an application to 5 months has decreased significantly the number of complaints (a limit of 4.5 months is determined by the EC's procedures). Awards are sent out by institutes, and the first are now reaching successful applicants.

For the first two rounds, postdocs accounted for $54 \%$ of eligible applications ( $23 \%$ in physics) of which $25 \%$ ( $26 \%$ for physics) were successful; predocs accounted for $42 \%$ eligible applications ( $19 \%$ in physics) of which only $11 \%$ (10 \% for physics) were successful. So postdocs are more successful than predocs, reflecting Council's policy that TMR grants be aimed at postdocs, and the inclusion of economics has tended to increase the number of predoc applications.

What is surprising is the poor response by experienced scientists. Only 95 applied in the first two rounds and a massive $82 \%$ were successful. Many more could have been funded.

The impact of TMR grants is judged to be considerable and fellows are being honoured by naming them Marie Curie Fellows. A major concern has been that TMR grants stimulate a brian drain to prosperous regions, so one-year return grants to help resettle postdocs have been created. In the first two rounds, 20 eligible applications were in physics and $85 \%$ were successful.

The next TMR training grant call closes on 15 June, with the following calls as planned every six months. Some Institutional Fellowships left over from $\mathrm{HCM}$ can be applied for until 7 June. Applicants must first approach a preselected institute. The EC says it will publish the list of institutes on WWW, presumably via the TMR homepage (http://www2.cordis.lu/ $\mathrm{tmr} / \mathrm{src} / \mathrm{tmr})$.

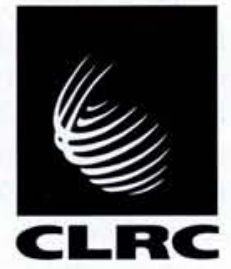

CALL FOR PROPOSALS

\section{EU - Funded Access to the Central Laser Facility Rutherford Appleton Laboratory}

The Central Laser Facility at the Rutherford Appleton Laboratory operates one of Europe's premier laser laboratories for research in pure and applied science including ICF, $x$-ray lasers, basic plasma physics, chemistry, biology and x-ray source applications.

Facilities include large scale $\mathrm{Nd}$ :glass and $\mathrm{KrF}$ lasers delivering focused intensities in excess of $10^{19} \mathrm{~W} . \mathrm{cm}^{-2}$, a dual-wavelength tuneable OPO system for ultra fast spectroscopy, a 110ps resolution confocal microscope and a $10 \mathrm{~Hz}$ laser plasma $\mathrm{x}$-ray source. See also http://www.nd.rl.ac.uk/lasers/

Applications for beam time are invited from EU and UK based scientists for experiments in the period July December 1996.

Contact Chris Edwards for further details of the facilities available and an application form.

E-mail: c.b.edwards@rl.ac.uk; $\quad$ Fax: +44 (0) 1235445888

Complete applications must be received by 22 April 1996 . 